\title{
Composite Nanofibers of Polyacrylonitrile (PAN) and Amino-functionalized Carbon Nanotubes Electrospun from Dimethylsulfoxide
}

\author{
Olcay EREN ${ }^{1}$, Nuray UCAR ${ }^{2}$, Aysen ONEN $^{3}$, Nuray KIZILDAG ${ }^{2}$ \\ ${ }^{1}$ Istanbul Technical University, Polymer Science and Technology, Istanbul, Turkey. \\ ${ }^{2}$ Istanbul Technical University, Department of Textile Engineering, Istanbul, Turkey. \\ ${ }^{3}$ Istanbul Technical University, Department of Chemistry, Istanbul, Turkey.
}

\begin{abstract}
In this study, DMSO was used as the solvent and PAN nanofibers reinforced with amino-functionalized multiwalled carbon nanotubes (f-MWCNTs) were successfully electrospun from the electrospinning solutions prepared in DMSO. The concentrations of f-MWCNTs were changed as $1 \mathrm{w} \%$ and $3 \mathrm{w} \%$ with respect to the weight of PAN. The effect of f-MWCNT concentration on morphology, conductivity and mechanical properties of composite nanofibers were examined and compared to that of pure PAN nanofibers. Uniform composite nanofibers were obtained. The diameters of the nanofibers were in the range of 515-536 nm. The addition of the f-MWCNTs resulted in an increase in nanofiber diameter. 3w\% f-MWCNT loaded PAN/f-MWCNT nanofiber showed the best mechanical properties. Conductivity increased with the incorporation of amino-functionalized multiwalled carbon nanotubes.
\end{abstract}

Keywords: nanotubes, conductive, electrospinning, nanocomposite, nanofiber, polyacrylonitrile.

\section{INTRODUCTION}

Carbon nanotubes (CNTs) are of great interest in nanotechnology because of their superior structural, mechanical, chemical, thermal, and electrical properties [1]. In order to effectively transfer their superior properties to nanocomposites, homogeneous dispersion of nanotubes in the polymer and strong interfacial bonding between the nanotubes and polymers should be achieved. Functionalization of CNTs is an effective way for strong interfacial bonding and homogeneous dispersion. There are several approaches for functionalization of CNTs such as defect functionalization, covalent functionalization, and noncovalent functionalization $[2,3]$.

In literature there are many studies in which different types of polymers such as polyacrylonitrile, polyvinyl alcohol, polyamide, polypropylene, polyaniline, etc. are reinforced with carbon nanotubes [4-7]. In most of the studies related with the investigation of reinforcing effect of CNTs in PAN/CNT composite nanofibers DMF has been used as the solvent [8-10]. However, the solvent type is reported to be very effective on the dispersion quality of the nanotubes and consequently the mechanical properties of the polymer composites produced with the addition of the carbon nanotubes [11].

In this study, instead of the widely used solvent, DMF, in studies related with polyacrylonitrile, DMSO was used as the solvent and PAN nanofibers reinforced with aminofunctionalized multiwalled carbon nanotubes (f-MWCNTs) were electrospun from the electrospinning solutions prepared in DMSO and the effect of f-MWCNT concentration on morphology, conductivity and mechanical properties of composite nanofibers were examined.

\section{MATERIALS AND METHOD}

\subsection{Materials}

Polyacrylonitrile (PAN) (Sigma Aldrich, 181315, average Mw: $150.000 \mathrm{~g} / \mathrm{mol}$ ) and dimethylsulfoxide (DMSO) were used as received while the multiwalled carbon nanotubes (MWCNTs) (diameter: 60-100 nm, length: 5-15 $\mu \mathrm{m}$ ) were used after functionalization. For functionalization, they were carboxy-functionalized and then aminofunctionalized. Nitric acid (HNO3), sulfuric acid (H2SO4), sodium hydroxide $(\mathrm{NaOH})$, sodium nitrite (NaNO2),

Corresponding Author: Nuray KIZILDAĞ, Tel: +90 (212) 51141 88, E-mail: kizildagn@itu.edu.tr Submitted: 15 October 2014, Revised: 04 March 2015, Accepted: 01 July 2015 
isophorone diamine (C10H22N2), N,N-dimethylformamide (DMF) and Whatman $0,45 \mu \mathrm{m}$ PTFE filter were used in the functionalization of MWCNTs.

\subsection{Method}

\subsubsection{CNT functionalization}

The carboxyl-functionalization was performed according to the method of Gao et al.'s [12], while the aminofunctionalization was performed according to the method of Zhao et al. [13].

\subsubsection{Preparation of the solutions}

$1 \mathrm{w} \%$ and $3 \mathrm{w} \%$ f-MWCNT (with respect to the weight of PAN) were added to the required amount of DMSO and homogenized with ultrasonic tip for 10 minutes and with ultrasonic bath for $45 \mathrm{~min}$. Then PAN was added to the dispersion. The solution was stirred with a magnetic stirrer at $40^{\circ} \mathrm{C}$ for 3 hours. The concentration of PAN was kept constant as $7 \mathrm{w} \%$ (with respect to the weight of the solution).

\subsubsection{Electrospinning}

A horizontal electrospinning setup was used. It contained a high voltage power supply $(0-50 \mathrm{kV})$, syringe pump and a grounded rotating collector. The electrospinning solution was put in a syringe of $10 \mathrm{~mL}$ and fed through a capillary tip with a diameter of $1.25 \mathrm{~mm}$. During electrospinning, the applied voltage was $15 \mathrm{kV}$, the distance between the tip and the collector was $10 \mathrm{~cm}$ and the flow rate of the spinning solution was $1 \mathrm{~mL} / \mathrm{h}$.

\subsubsection{Characterization}

SEM images of pure PAN and composite nanofiber samples were taken with scanning electron microscope (SEM; EVO MA 10). The diameters of at least 50 randomly selected nanofibers were measured on SEM photomicrographs. The average nanofiber diameters were calculated after the measuring the fibre diameters using Image Analysis Software. Mechanical properties of the nanowebs were measured using a tensile tester with a $100 \mathrm{~N}$ load cell at a crosshead speed of $20 \mathrm{~mm} / \mathrm{min}$. The length and width of the specimens were $35 \mathrm{~mm}$ and $5 \mathrm{~mm}$, respectively. The gage length was $15 \mathrm{~mm}$, and at least 10 specimens were tested for each sample. The thicknesses of the specimens were measured with a Mitutoyo digital micrometre. Resistance measurements were performed using a two-probe system connected to Microtest 6370 LCR meter with four-wire system. Conductivity in $\mathrm{S} / \mathrm{cm}$ was calculated using the volume resistance value measured and the geometric dimensions of the samples. For the calculation of volumetric conductivity, the thicknesses of the samples were measured with the integrated thickness meter.

\section{RESULTS AND DISCUSSION}

\subsection{Morphology}

The SEM images of the pure PAN and composite nanowebs taken with $2.5 \mathrm{kX}$ magnification can be seen in Figure 1.

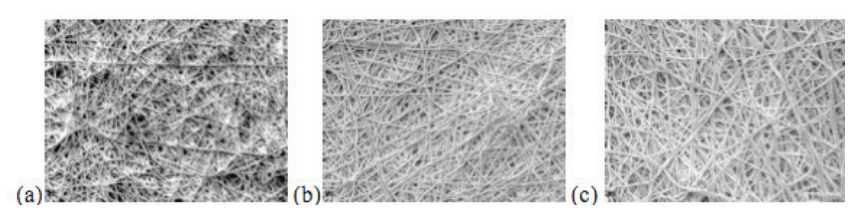

Figure 1. SEM images of (a) pure PAN, (b) $1 \mathrm{w} \%$ f-MWCNT2/PAN, (c) 3w\% f-MWCNT/PAN

The nanofibers had uniform structures. In parallel with the literature [14], the average diameter of the nanofibers increased slightly with the addition of f-MWCNTs. While the diameter of pure PAN nanofibers was $515.34 \mathrm{~nm}, 1$ and $3 \mathrm{w} \% \mathrm{f}-\mathrm{MWCNT}$ addition resulted in diameters of $536 \mathrm{~nm}$ and $531 \mathrm{~nm}$, respectively. The increase in diameter was attributed to the increase in the electrospinning solution viscosity with the addition of carbon nanotubes.

\subsection{Mechanical Properties}

Table 1 shows the mechanical properties of pure PAN and nanocomposite nanofibers produced with the addition of amino-functionalized MWCNTs.

Table 1. Mechanical properties of composite nanofibers.

\begin{tabular}{cccc}
\hline Samples & $\begin{array}{c}\text { Breaking } \\
\text { Strength } \\
(\mathrm{MPa})\end{array}$ & $\begin{array}{c}\text { Breaking } \\
\text { Elongation } \\
(\%)\end{array}$ & $\begin{array}{c}\text { E-modulus } \\
(\mathrm{MPa})\end{array}$ \\
PAN-DMSO & 8.64 & 8.95 & 100.59 \\
& & & \\
1w\% f-MWCNT/PAN & 8.99 & 9.70 & 38.23 \\
& & & \\
3w\% f-MWCNT/PAN & 9.35 & 14.0 & 95.70 \\
\hline
\end{tabular}


The breaking strength and breaking elongation values increased with addition of $\mathrm{f}-\mathrm{CNTs}$ while the E-modulus values varied. There was an increase of $8.2 \%$ in breaking strength while there was an increase of $56.4 \%$ in breaking elongation with the addition $3 \mathrm{w} \%$ amino-functionalized carbon nanotubes. In order to achieve significant improvements in the mechanical properties of the polymer composites with carbon nanotubes, the main challenge is to obtain a good dispersion of carbon nanotubes $[15,16]$. The small increase in breaking strength accompanied by a high increase in breaking elongation was most likely due to the agglomeration of carbon nanotubes and void formation around the agglomerates.

\subsection{Conductivity}

Table 2. Conductivity values of nanocomposite nanofibers.

\begin{tabular}{cccc}
\hline Samples & $\begin{array}{c}\text { Conductivity } \\
\text { S/cm }\end{array}$ & $\begin{array}{c}\text { Standard } \\
\text { deviation }\end{array}$ & $\begin{array}{c}\text { Coefficient } \\
\text { of variation }\end{array}$ \\
$\begin{array}{c}1 \mathrm{w} \% \text { f-MWCNT/ } \\
\text { PAN }\end{array}$ & $2.80 * 10^{-8}$ & $3.09 * 10^{-9}$ & 14.00 \\
$\begin{array}{c}3 \mathrm{w} \% \text { f-MWCNT/ } \\
\text { PAN }\end{array}$ & $2.10^{*} 10^{-8}$ & $7.77 * 10^{-9}$ & 37.19 \\
\hline
\end{tabular}

Pure PAN nanofibers are insulators with a reported conductivity value of 10-12 S/cm [17]. The addition of functionalized carbon nanotubes resulted in an increase in the conductivity of PAN nanofibers. The conductivity was measured as $10-8 \mathrm{~S} / \mathrm{cm}$ for both of the nanocomposite nanowebs produced. Thus they are expected to be used in electrostatic dissipation applications [18]. The $\mathrm{cv} \%$ of the conductivity was lower for the carbon nanotube content of $1 \mathrm{w} \%$ which showed that the distribution of carbon nanotubes was better when the carbon nanotube amount was $1 \mathrm{w} \%$.

\section{CONCLUSIONS}

Polyacrylonitrile nanofibers with functionalized carbon nanotubes from electrospinning solutions prepared with DMSO were successfully electrospun at the f-MWCNT loadings of 1 and $3 \mathrm{w} \%$. It was demonstrated in this study that dimethylsulfoxide was a suitable solvent for the dispersion of the functionalized carbon nanotubes at $3 \mathrm{w} \%$ loading. There was slight increase in nanofiber diameter with the addition of f-MWCNTs. The composite nanofibers showed some improvement on mechanical properties and conductivity. The breaking strength improved $8.2 \%$ with respect to that of pure polyacrylonitrile nanoweb and the breaking elongation improved $56.4 \%$. The conductivity of the composite polyacrylonitrile nanowebs was on the order of 10-8 $\mathrm{S} /$ $\mathrm{cm}$ and thus they can be used in antistatic applications. It was concluded that amino-functionalized MWCNTs could be used as filler resulting in some improvement in both mechanical properties and conductivity of the nanowebs.

\section{ACKNOWLEDGEMENT}

We would like to thank to TUBITAK for supporting this study with Project (112M877).

\section{REFERENCES}

[1] Ge JJ, Hou H, Li Q, Graham MJ, Greiner A, Reneker DH, Harris FW, Cheng SZD, Assembly of WellAligned Multiwalled Carbon Nanotubes in Confined Polyacrylonitrile Environments: Electrospun Composite Nanofiber Sheets, J. Am. Chem. Soc. 2004, 126, 15754-15761.

[2] Coleman JN, Khan U, Gun'ko YK, Mechanical Reinforcement of Polymers Using Carbon Nanotubes, Adv. Mater., 2006, 18, 689-706.

[3] Sahoo NG, Chenga HKF, Caia J, Li L, Chan SH, Zhaob $\mathrm{J}$, Yub S, Improvement of mechanical and thermal properties of carbon nanotube composites through nanotube functionalization and processing methods, Mater. Chem. Phys., 2009, 117, 313-320.

[4] Wang K, Gu M, Wang J, Qin C, Dai L, Functionalized carbon nanotube/polyacrylonitrile composite nanofibers: fabrication and properties, Polym. Adv. Technol., 2012, 23, 262-271.

[5] Hou H, Ge JJ, Zeng J, Li Q, Reneker DH, Greiner A, Cheng SZD, Electrospun Polyacrylonitrile Nanofibers Containing a High Concentration of Well-Aligned Multiwall Carbon Nanotubes, Chem Mater, 2005, 17, 967.

[6] Xue P, KH Park, XM Tao, W Chen, XY Cheng, Electrically conductive yarns based on PVA/carbon nanotubes. Composite Structures, 2007, 78(2), 271277.

[7] Wang CY, V Mottaghitalab, CO Too, GM Spinks, GG 
Wallace, Polyaniline and polyaniline-carbon nanotube composite fibres as battery materials in ionic liquid electrolyte, Journal of Power Sources, 2007, 163 (2), 1105-1109.

[8] Hou H, Ge JJ, Zeng J, Li Q, Reneker DH, Greiner A, Cheng, SZD, Electrospun Polyacrylonitrile Nanofibers Containing a High Concentration of Well-Aligned Multiwall Carbon Nanotubes, Chem Mater, 2005, 17, 967.

[9] Saeed K, Park SY, Preparation and characterization of multiwalled carbon nanotubes/polyacrylonitrile nanofibers, J Polym Res, 2010, 17, 535-540.

[10] Chen IH, Wang CC, Chen CY, Fabrication and Structural Characterization of Polyacrylonitrile and Carbon Nanofibers, Containing Plasma-Modified Carbon Nanotubes by Electrospinning, J. Phys. Chem. C, 2010, 114, 13532-13539.

[11] Umar Khan, Kevin Ryan, Werner J. Blau, Jonathan N. Coleman, The effect of solvent choice on the mechanical properties of carbon nanotube-polymer composites, Composites Science and Technology, 2007, 67, 3158-3167.

[12] Gao C, Vo DC, Jin ZY, Li W, Armes SP, Macromolecules
$2005,38,8634-8648$.

[13] Zhao Z, Yang Z, Hu Y, Li J, Fan X, Applied surface science, 2013, 25409, 6 .

[14]HeikkiläP, Harlin A, Electrospinning of polyacrylonitrile (PAN) solution: Effect of conductive additive and filler on the process, eXPRESS Polymer Letters, 2009, 3(7), 437-445.

[15] Coleman JN, Khan U, Gun'ko YK, Mechanical Reinforcement of Polymers Using Carbon Nanotubes. Adv. Mater., 2006, 18, 689-706.

[16] Sahoo NG, Chenga HKF, Caia J, Li L, Chan SH, Zhaob $\mathrm{J}$, Yub S, Improvement of mechanical and thermal properties of carbon nanotube composites through nanotube functionalization and processing methods. Mater. Chem. Phys., 2009, 117, 313-320.

[17] Almuhamed N, Khenoussi L, Schacher D, Adolphe HB, Measuring of Electrical Properties of MWNTReinforced PAN Nanocomposites, Journal of Nanomaterials, 2012, 1-7.

[18] Saini P, Choudhary V, Electrostatic charge dissipation and electromagnetic interference shielding response of polyaniline based conducting fabrics, Indian Journal of Pure Applied Physics, 2013, 51, 112-117. 